\title{
ANÁLISIS DE LA VARIABILIDAD MORFOLÓGICA DEL “AÑU” Tropaeolum tuberosum Ruiz \& Pavón PROCEDENTE DE NUEVE DISTRITOS DE LA REGIÓN CUSCO
}

\section{ANALYSIS OF MORPHOLOGICAL VARIABILITY OF THE "AÑU" Tropaeolum tuberosum Ruiz \& Pavón FROM NINE DISTRICTS OF CUSCO REGION}

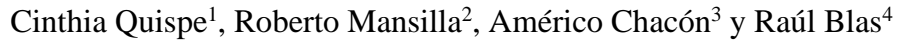

\begin{abstract}
Resumen
El añu es un cultivo andino subutilizado con potencialidades para su uso en la alimentación y en la industria farmacéutica debido a su capacidad antioxidante y la presencia de glucosinolatos. Sin embargo, por su bajo consumo estaría afrontando posibles problemas de pérdida de variabilidad. Por esta razón, en el presente trabajo se caracterizó y determinó la variabilidad morfológica de 89 accesiones recolectadas en 9 distritos de la Región Cusco. Los caracteres utilizados en la caracterización morfológica fueron evaluados para su uso mediante el coeficiente de variabilidad, análisis de correlación y de componentes principales, determinándose que los caracteres de la flor y de tubérculo son los que mejor evalúan la variabilidad del germoplasma utilizado. En el análisis de agrupamiento utilizando 31 caracteres se determinaron 89 morfotipos distribuidos en 4 grupos con un coeficiente de distancia de 1.45. Los grupos I y II están conformados por añus de tubérculos de color amarillo y anaranjado, mientras que los grupos III y IV son de añus de color rojo grisáceo, púrpura grisáceo y negro. La ausencia de duplicados, sugiere que a pesar de ser un cultivo subutilizado y que se propaga vegetativamente, el añu aún mantiene una amplia variabilidad morfológica en la Región Cusco.

Palabras clave: Añu, mashua, Tropaeolum tuberosum, análisis de variabilidad, caracterización morfológica.
\end{abstract}

\begin{abstract}
Añu is an underutilized Andean crop. Its tuber has the potentiality to be used in the food and pharmaceutical industries due its glucosinolates content and antioxidant capacity. However, añu could be facing potential problems such as loss of variability due to low consumption. For this reason, in this study 89 accessions collected from 9 districts in the Cusco region were characterized and their morphological variability was determined. The characters used in the morphological characterization were assessed for use their by the coefficient of variability, correlation and principal component analysis. The flower and tubers characters best assess the variability of the germplasm. In the cluster analysis using 31 characters, 89 morphotypes were determined distributed into 4 groups with a distance coefficient of 1.45 . Groups I and II have yellow and orange tubers, while Groups III and IV have red gray, purple gray and black tubers. The absence of duplicates, suggests that despite its clonal reproduction and its underutilization, añu still maintains a wide morphological variability in Cusco Region.
\end{abstract}

Key words: Añu, mashua, Tropaeolum tuberosum, variability analysis, morphological characterization.

\section{Introducción.}

El añu es un tubérculo originario de la región andina central y es catalogado como el cuarto en importancia en esta zona, después de la papa, Oca y Olluco, siendo cultivado en los andes de Bolivia, Perú, Ecuador, Colombia y Venezuela (Gibbs et al., 1978). Desde el punto de vista agronómico es muy rústico ya que en la zona andina se cultiva en suelos pobres, sin uso de fertilizantes ni pesticidas, y aun en estas condiciones, sus rendimientos superan a los de la papa. Además, de ser tolerante a las heladas, también tiene capacidad fungicida, nematocida e insecticida, debido a los glucosinolatos y sus derivados los isotiocianatos (Ortega et al., 2006) presentes en toda la planta. El origen de estas cualidades agronómicas, puede deberse a que el añu ha evolucionado en las zonas más inhóspitas para la agricultura ya que los pobladores precolombinos hicieron un uso eficiente de 


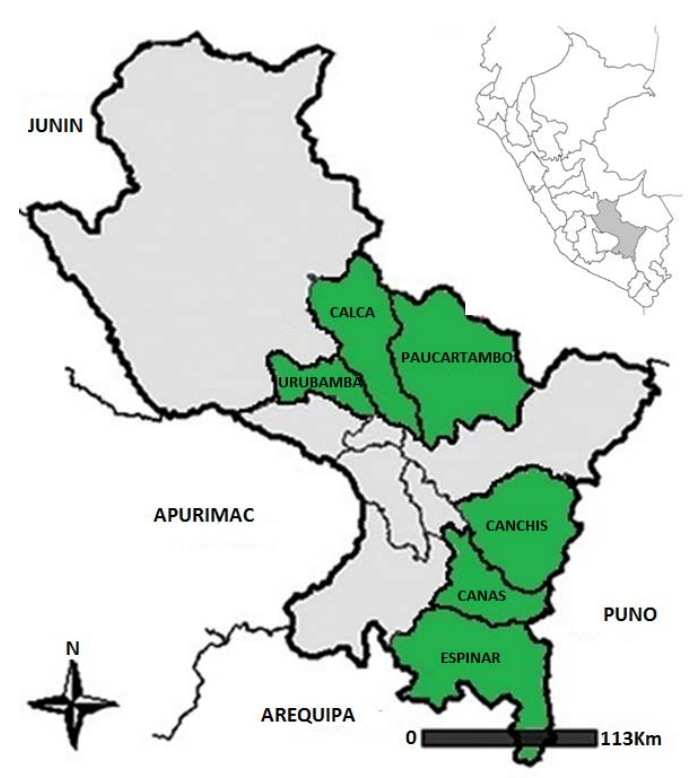

Figura 1. Mapa de la Región Cusco donde se muestra sombreado en verde las provincias de los distritos de donde provienen las accesiones de añu analizadas.

las tierras marginales (King, 1987). Nutricionalmente es un cultivo importante, por su alto contenido de vitamina $\mathrm{C}$ y proteínas, el cual supera al de la leche materna (Espinoza et al., 1999). Existen muchos reportes experimentales de propiedades medicinales del añu que son resultado de la presencia de glucosinolatos y sus derivados principalmente de pmethoxybenzylisothiocyanate (Johns et al., 1982), y de Bencil-isotiocianato, siendo este último un agente anticancerígeno, que actúa eficazmente contra una amplia gama de células tumorales (Hasegawa et al., 1992; Pintao et al., 1995). Así mismo, el añu comparado con la papa, el olluco, y la oca presenta una mayor capacidad antioxidante, con alto contenido de antocianinas y carotenoides (Campos et al., 2006). Atributos que hacen del añu un cultivo con un gran potencial, y que podrían ser utilizados en la mejora para la resistencia a plagas, la industria farmacéutica y en la nutrición.

Actualmente, los pobladores andinos más pobres lo usan en su alimentación y forma parte de su cultura, y junto con la papa, la oca y el olluco son importantes para su subsistencia. Es precisamente en las parcelas de dichos agricultores donde la diversidad del añu aún se conserva, sin embargo, en zonas donde se han introducido cultivos con mayor demanda del mercado o la actividad agrícola, viene siendo reemplazado por otros económicamente más rentables, por ello, la diversidad de este cultivo viene disminuyendo.

En la actualidad no existe un grupo de caracteres morfológicos que puedan ser utilizados como descriptores estandarizados para el estudio de la diversidad del añu, y las pocas investigaciones realizadas indican a la Región Cusco como la zona que estaría albergando la mayor variabilidad de este cultivo. En consecuencia en este trabajo se han determinado los caracteres morfológicos que evalúan mejor la variabilidad mofológica y que podrían formar parte de una lista de descriptores para el estudio de la diversidad de añu. Así mismo, se ha realizado el análisis de la variabilidad morfológica del germoplasma de añu proveniente de 9 distritos alto andinos de la Región Cusco.

\section{Materiales y métodos.}

Área de Estudio y Material vegetal.

El material vegetal utilizado proviene de un jardín de conservación ubicado en la comunidad campesina de Viacha, Distrito de Pisac a $3800 \mathrm{~m}$ de altitud, a $13^{\circ}$ $21^{\prime} 40^{\prime \prime}$ ' de latitud sur, $71^{\circ} 49^{\prime} 28^{\prime}$ ' de longitud Oeste. Dicho material fue recolectado en nueve distritos de la Región Cusco (Tabla 1 y Figura 1).

Manejo de campo.

Se realizó siguiendo las prácticas tradicionales de la comunidad de Viacha, motivo por el cual la parcela experimental y el agricultor conservacionista encargado del manejo fue designado por la misma comunidad campesina. La siembra, labores culturales y de cosecha se realizaron de acuerdo al calendario astronómico andino reportado por Moscoso (2007). Por ser el añu un cultivo rastrero con tallos y peciolos volubles capaces de trepar a cualquier tipo de apoyo, se realizaron modificaciones en las medidas de las parcelas tradicionales, con la finalidad de facilitar la evaluación morfológica (Anexo 1). Se sembraron 3 repeticiones por accesión a un distanciamiento de 30 $\mathrm{cm}$ en surcos de $90 \mathrm{~cm}$ de largo colocando dos ó tres semillas vegetativas por cada repetición (Anexo 2). El primer aporque se realizó a los 102 días y tuvo la finalidad de abrir un canal entre los surcos y eliminar los arvenses; el segundo se efectuó a los 30 días después del primero con el propósito de favorecer un mayor desarrollo de estolones y la tuberización. La cosecha se realizó a los 240 días después de la siembra.

Análisis de caracteres morfológicos.

Los caracteres utilizados (Anexo 3) fueron seleccionados a partir de los empleados por Durand (2005) y Moscoso (2007), eliminando aquellos que no presentaban variación o no mostraron uniformidad dentro de una misma planta (Tabla 2). Además, se determinaron los coeficientes de variación, y se efectuaron los análisis de correlación de Pearson y de Componentes Principales con el paquete estadístico NTSYS-pc versión 2.1 (Rohlf, 2000). 
Tabla 1. Registro de los datos pasaporte de las 89 accesiones de añu recolectadas en 9 Distritos de la Región Cusco, que fueron utilizados como material vegetal.

\begin{tabular}{|c|c|c|c|c|c|c|c|c|}
\hline Identificación & Región & Provincia & Distrito & Localidad & Altitud & Latitud Sur & Longitud Oeste & Nombre Común \\
\hline ACC 002 & Cusco & Calca & Lamay & Huama & 3692 & $13^{\circ} 20^{\prime} 14,3^{\prime \prime}$ & $71^{\circ} 52^{\prime} 11,0^{\prime \prime}$ & Puka Soqo Ninrin \\
\hline ACC 003 & Cusco & Calca & Lamay & Huama & 3692 & $13^{\circ} 20^{\prime} 14,3^{\prime \prime}$ & $71^{\circ} 52^{\prime} 11,0^{\prime \prime}$ & Sayllaseray \\
\hline ACC 004 & Cusco & Calca & Lamay & Huama & 3692 & $13^{\circ} 20^{\prime} 14,3^{\prime \prime}$ & $71^{\circ} 52^{\prime} 11,0^{\prime \prime}$ & Oqe Puma \\
\hline ACC 005 & Cusco & Calca & Lamay & Huama & 3692 & $13^{\circ} 20^{\prime} 14,3^{\prime \prime}$ & $71^{\circ} 52^{\prime} 11,0^{\prime \prime}$ & Yana Soqo \\
\hline ACC 007 & Cusco & Calca & Lamay & Huama & 3692 & $13^{\circ} 20^{\prime} 14,3^{\prime \prime}$ & $71^{\circ} 52^{\prime} 11,0^{\prime \prime}$ & Oqe Puma Maqui \\
\hline ACC 008 & Cusco & Calca & Lamay & Huama & 3692 & $13^{\circ} 20^{\prime} 14,3^{\prime \prime}$ & $71^{\circ} 52^{\prime} 11,0^{\prime \prime}$ & Asno Wañuchi \\
\hline ACC 009 & Cusco & Calca & Lamay & Huama & 3692 & $13^{\circ} 20^{\prime} 14,3^{\prime \prime}$ & $71^{\circ} 52^{\prime} 11,0^{\prime \prime}$ & Puka Sayllaseray \\
\hline ACC 010 & Cusco & Calca & Lamay & Huama & 3692 & $13^{\circ} 20^{\prime} 14,3^{\prime \prime}$ & $71^{\circ} 52^{\prime} 11,0^{\prime \prime}$ & Taruka Asta \\
\hline ACC 011 & Cusco & Calca & Lamay & Huama & 3692 & $13^{\circ} 20^{\prime} 14,3^{\prime \prime}$ & $71^{\circ} 52^{\prime} 11,0^{\prime \prime}$ & Zapallo Chupasapa \\
\hline ACC 012 & Cusco & Calca & Lamay & Huama & 3692 & $13^{\circ} 20^{\prime} 14,3^{\prime \prime}$ & $71^{\circ} 52^{\prime} 11,0^{\prime \prime}$ & Yana Ñahui \\
\hline ACC 013 & Cusco & Calca & Lamay & Huama & 3692 & $13^{\circ} 20^{\prime} 14,3^{\prime \prime}$ & $71^{\circ} 52^{\prime} 11,0^{\prime \prime}$ & Urpi Runtu \\
\hline ACC 014 & Cusco & Calca & Lamay & Huama & 3692 & $13^{\circ} 20^{\prime} 14,3^{\prime \prime}$ & $71^{\circ} 52^{\prime} 11,0^{\prime \prime}$ & Puka Marcos \\
\hline ACC 017 & Cusco & Calca & Lamay & Huarqui & 3692 & $13^{\circ} 20^{\prime} 14,3^{\prime \prime}$ & $71^{\circ} 52^{\prime} 11,0^{\prime \prime}$ & Puka Zapallo \\
\hline ACC 018 & Cusco & Calca & Lamay & Huilloc & 3692 & $13^{\circ} 20^{\prime} 14,3^{\prime \prime}$ & $71^{\circ} 52^{\prime} 11,0^{\prime \prime}$ & Q'ello Qasqa \\
\hline ACC 019 & Cusco & Calca & Lamay & Huama & 3692 & $13^{\circ} 20^{\prime} 14,3^{\prime \prime}$ & $71^{\circ} 52^{\prime} 11,0^{\prime \prime}$ & Q'ello Pitiquiña \\
\hline ACC 021 & Cusco & Calca & Lamay & Huama & 3692 & $13^{\circ} 20^{\prime} 14,3^{\prime \prime}$ & $71^{\circ} 52^{\prime} 11,0^{\prime \prime}$ & Yana Pitiquiña \\
\hline ACC 022 & Cusco & Calca & Lamay & Huama & 3692 & $13^{\circ} 20^{\prime} 14,3^{\prime \prime}$ & $71^{\circ} 52^{\prime} 11,0^{\prime \prime}$ & Ñut'u Yanañahui \\
\hline ACC 024 & Cusco & Calca & Lamay & Huama & 3692 & $13^{\circ} 20^{\prime} 14,3^{\prime \prime}$ & $71^{\circ} 52^{\prime} 11,0^{\prime \prime}$ & Puka Mact'illo \\
\hline ACC 025 & Cusco & Calca & Lamay & Huama & 3692 & $13^{\circ} 20^{\prime} 14,3^{\prime \prime}$ & $71^{\circ} 52^{\prime} 11,0^{\prime \prime}$ & Oqe Taruka Asta \\
\hline ACC 026 & Cusco & Calca & Lamay & Huama & 3692 & $13^{\circ} 20^{\prime} 14,3^{\prime \prime}$ & $71^{\circ} 52^{\prime} 11,0^{\prime \prime}$ & Q'ello Añu \\
\hline ACC 027 & Cusco & Calca & Lamay & Huama & 3692 & $13^{\circ} 20^{\prime} 14,3^{\prime \prime}$ & $71^{\circ} 52^{\prime} 11,0^{\prime \prime}$ & Yana Ruckii \\
\hline ACC 029 & Cusco & Calca & Lamay & Huama & 3692 & $13^{\circ} 20^{\prime} 14,3^{\prime \prime}$ & $71^{\circ} 52^{\prime} 11,0^{\prime \prime}$ & Puka Soqo \\
\hline ACC 030 & Cusco & Calca & Lamay & Huama & 3692 & $13^{\circ} 20^{\prime} 14,3^{\prime \prime}$ & $71^{\circ} 52^{\prime} 11,0^{\prime \prime}$ & Phuña Añu \\
\hline ACC 031 & Cusco & Calca & Lamay & Huama & 3692 & $13^{\circ} 20^{\prime} 14,3^{\prime \prime}$ & $71^{\circ} 52^{\prime} 11,0^{\prime \prime}$ & Añu Inca Patacahuayoc \\
\hline ACC 032 & Cusco & Calca & Lamay & Huama & 3692 & $13^{\circ} 20^{\prime} 14,3^{\prime \prime}$ & $71^{\circ} 52^{\prime} 11,0^{\prime \prime}$ & Oqe Charita \\
\hline ACC 033 & Cusco & Calca & Lamay & Huama & 3692 & $13^{\circ} 20^{\prime} 14,3^{\prime \prime}$ & $71^{\circ} 52^{\prime} 11,0^{\prime \prime}$ & Oqe P'asña \\
\hline ACC 034 & Cusco & Calca & Lamay & Huama & 3692 & $13^{\circ} 20^{\prime} 14,3^{\prime \prime}$ & $71^{\circ} 52^{\prime} 11,0^{\prime \prime}$ & Q'ello Waca Waqra \\
\hline ACC 035 & Cusco & Calca & Lamay & Huilloc & 3692 & $13^{\circ} 20^{\prime} 14,3^{\prime \prime}$ & $71^{\circ} 52^{\prime} 11,0^{\prime \prime}$ & Oqe Waca Waqra \\
\hline ACC 036 & Cusco & Calca & Lamay & Huama & 3692 & $13^{\circ} 20^{\prime} 14,3^{\prime \prime}$ & $71^{\circ} 52^{\prime} 11,0^{\prime \prime}$ & Yurac Pusqo \\
\hline ACC 037 & Cusco & Calca & Lamay & Huama & 3692 & $13^{\circ} 20^{\prime} 14,3^{\prime \prime}$ & $71^{\circ} 52^{\prime} 11,0^{\prime \prime}$ & Puka Zanahoria \\
\hline ACC 038 & Cusco & Calca & Lamay & Huama & 3692 & $13^{\circ} 20^{\prime} 14,3^{\prime \prime}$ & $71^{\circ} 52^{\prime} 11,0^{\prime \prime}$ & Platano Añu \\
\hline ACC 039 & Cusco & Calca & Lamay & Huama & 3692 & $13^{\circ} 20^{\prime} 14,3^{\prime \prime}$ & $71^{\circ} 52^{\prime} 11,0^{\prime \prime}$ & Yurac Yanañahui \\
\hline ACC 040 & Cusco & Calca & Lamay & Huama & 3692 & $13^{\circ} 20^{\prime} 14,3^{\prime \prime}$ & $71^{\circ} 52^{\prime} 11,0^{\prime \prime}$ & Waca Waqra \\
\hline ACC 041 & Cusco & Calca & Lamay & Huama & 3692 & $13^{\circ} 20^{\prime} 14,3^{\prime \prime}$ & $71^{\circ} 52^{\prime} 11,0^{\prime \prime}$ & Yana Zanahoria \\
\hline ACC 042 & Cusco & Calca & Lamay & Huama & 3692 & $13^{\circ} 20^{\prime} 14,3^{\prime \prime}$ & $71^{\circ} 52^{\prime} 11,0^{\prime \prime}$ & Yawar Wacac \\
\hline ACC 043 & Cusco & Calca & Lamay & Huama & 3692 & $13^{\circ} 20^{\prime} 14,3^{\prime \prime}$ & $71^{\circ} 52^{\prime} 11,0^{\prime \prime}$ & Yana Oqe Pitiquiña \\
\hline ACC 044 & Cusco & Calca & Lamay & Huama & 3692 & $13^{\circ} 20^{\prime} 14,3^{\prime \prime}$ & $71^{\circ} 52^{\prime} 11,0^{\prime \prime}$ & Q'ello Zanahoria \\
\hline ACC 045 & Cusco & Calca & Lamay & Huama & 3692 & $13^{\circ} 20^{\prime} 14,3^{\prime \prime}$ & $71^{\circ} 52^{\prime} 11,0^{\prime \prime}$ & Yurac Mestiza \\
\hline ACC 046 & Cusco & Calca & Lamay & Huama & 3692 & $13^{\circ} 20^{\prime} 14,3^{\prime \prime}$ & $71^{\circ} 52^{\prime} 11,0^{\prime \prime}$ & Q'ello Qachun Wacachi \\
\hline ACC 047 & Cusco & Calca & Lamay & Huama & 3692 & $13^{\circ} 20^{\prime} 14,3^{\prime \prime}$ & $71^{\circ} 52^{\prime} 11,0^{\prime \prime}$ & Yurac Pusi \\
\hline ACC 049 & Cusco & Calca & Lamay & Huama & 3692 & $13^{\circ} 20^{\prime} 14,3^{\prime \prime}$ & $71^{\circ} 52^{\prime} 11,0^{\prime \prime}$ & Puka Qasqa \\
\hline ACC 050 & Cusco & Urubamba & Chincheros & Yanacona & 3733 & $13^{\circ} 23^{\prime} 42,3^{\prime \prime}$ & $72^{\circ} 05^{\prime} 0,21 "$ & Ñahuisapa \\
\hline ACC 051 & Cusco & Paucartambo & Paucartambo & Paucartambo & 3020 & $13^{\circ} 07^{\prime} 00^{\prime \prime}$ & $71^{\circ} 35^{\prime} 00^{\prime \prime}$ & Oqe añu \\
\hline ACC 052 & Cusco & Paucartambo & Paucartambo & Paucartambo & 3020 & $13^{\circ} 07^{\prime} 00^{\prime \prime}$ & $71^{\circ} 35^{\prime} 00^{\prime \prime}$ & Yana añu \\
\hline ACC 053 & Cusco & Paucartambo & Paucartambo & Paucartambo & 3020 & $13^{\circ} 07^{\prime} 00^{\prime \prime}$ & $71^{\circ} 35^{\prime} 00^{\prime \prime}$ & K'upa añu \\
\hline ACC 054 & Cusco & Paucartambo & Paucartambo & Paucartambo & 3020 & $13^{\circ} 07^{\prime} 00^{\prime \prime}$ & $71^{\circ} 35^{\prime} 00^{\prime \prime}$ & Waca waqra \\
\hline ACC 055 & Cusco & Urubamba & Chincheros & Yanacona & 3733 & $13^{\circ} 23^{\prime} 42,3^{\prime \prime}$ & $72^{\circ} 05^{\prime} 0,21^{\prime \prime}$ & Jasuti \\
\hline ACC 056 & Cusco & Calca & Pisac & Viacha & 4200 & $13^{\circ} 21^{\prime} 40^{\prime \prime}$ & $71^{\circ} 49^{\prime} 28^{\prime \prime}$ & Frutilla \\
\hline ACC 058 & Cusco & Urubamba & Chincheros & Yanacona & 3733 & $13^{\circ} 23^{\prime} 42,3^{\prime \prime}$ & $72^{\circ} 05^{\prime} 0,21^{\prime \prime}$ & Yana añu \\
\hline ACC 059 & Cusco & Calca & Pisac & Viacha & 4200 & $13^{\circ} 21^{\prime} 40^{\prime \prime}$ & $71^{\circ} 49^{\prime} 28^{\prime \prime}$ & Puka Cheqche \\
\hline ACC 060 & Cusco & Calca & Pisac & Viacha & 4200 & $13^{\circ} 21^{\prime} 40^{\prime \prime}$ & $71^{\circ} 49^{\prime} 28^{\prime \prime}$ & Q'ello suyt'u añu \\
\hline ACC 061 & Cusco & Calca & Pisac & Viacha & 4200 & $13^{\circ} 21^{\prime} 40^{\prime \prime}$ & $71^{\circ} 49^{\prime} 28^{\prime \prime}$ & Yurac suyt'u añu \\
\hline ACC 062 & Cusco & Paucartambo & Paucartambo & Paucartambo & 3020 & $13^{\circ} 07^{\prime} 00^{\prime \prime}$ & $71^{\circ} 35^{\prime} 00^{\prime \prime}$ & waca waqra \\
\hline ACC 064 & Cusco & Urubamba & Chincheros & Yanacona & 3733 & $13^{\circ} 23^{\prime} 42,3^{\prime \prime}$ & $72^{\circ} 05^{\prime} 0,21^{\prime \prime}$ & Piña añu \\
\hline ACC 065 & Cusco & Urubamba & Chincheros & Yanacona & 3733 & $13^{\circ} 23^{\prime} 42,3^{\prime \prime}$ & $72^{\circ} 05^{\prime} 0,21^{\prime \prime}$ & Asno huañuchi \\
\hline ACC 066 & Cusco & Calca & Pisac & Amaru & 3500 & $13^{\circ} 23^{\prime} 00^{\prime \prime}$ & $71^{\circ} 50^{\prime} 00^{\prime \prime}$ & Waca asta \\
\hline ACC 067 & Cusco & Urubamba & Chincheros & Yanacona & 3733 & $13^{\circ} 23^{\prime} 42,3^{\prime \prime}$ & $72^{\circ} 05^{\prime} 0,21^{\prime \prime}$ & Yawar waqac \\
\hline ACC 068 & Cusco & Calca & Pisac & Amaru & 3500 & $13^{\circ} 23^{\prime} 00^{\prime \prime}$ & $71^{\circ} 50^{\prime} 00^{\prime \prime}$ & Inca añu \\
\hline ACC 069 & Cusco & Paucartambo & Paucartambo & Paucartambo & 3020 & $13^{\circ} 07^{\prime} 00^{\prime \prime}$ & $71^{\circ} 35^{\prime} 00^{\prime \prime}$ & Amarillo \\
\hline ACC 070 & Cusco & Urubamba & Chincheros & Yanacona & 3733 & $13^{\circ} 23^{\prime} 42,3^{\prime \prime}$ & $72^{\circ} 05^{\prime} 0,21^{\prime \prime}$ & Platano añu \\
\hline ACC 071 & Cusco & Paucartambo & Paucartambo & Paucartambo & 3020 & $13^{\circ} 07^{\prime} 00^{\prime \prime}$ & $71^{\circ} 35^{\prime} 00^{\prime \prime}$ & Lisas añu \\
\hline ACC 072 & Cusco & Calca & Pisac & Amaru & 3500 & $13^{\circ} 23^{\prime} 00^{\prime \prime}$ & $71^{\circ} 50^{\prime} 00^{\prime \prime}$ & Zapallo \\
\hline ACC 073 & Cusco & Calca & Pisac & Amaru & 3500 & $13^{\circ} 23^{\prime} 00^{\prime \prime}$ & $71^{\circ} 50^{\prime} 00^{\prime \prime}$ & Yawar waqac \\
\hline ACC 074 & Cusco & Paucartambo & Paucartambo & Paucartambo & 3020 & $13^{\circ} 07^{\prime} 00^{\prime \prime}$ & $71^{\circ} 35^{\prime} 00^{\prime \prime}$ & Rumucha añu \\
\hline ACC 075 & Cusco & Urubamba & Chincheros & Yanacona & 3733 & $13^{\circ} 23^{\prime} 42,3^{\prime \prime}$ & $72^{\circ} 05^{\prime} 0,21^{\prime \prime}$ & Zapallo añu \\
\hline ACC 076 & Cusco & Paucartambo & Paucartambo & Paucartambo & 3020 & $13^{\circ} 07^{\prime} 00^{\prime \prime}$ & $71^{\circ} 35^{\prime} 00^{\prime \prime}$ & Chupasapa añu \\
\hline ACC 077 & Cusco & Paucartambo & Paucartambo & Paucartambo & 3020 & $13^{\circ} 07^{\prime} 00^{\prime \prime}$ & $71^{\circ} 35^{\prime} 00^{\prime \prime}$ & Q'ello Chupasapa \\
\hline ACC 078 & Cusco & Paucartambo & Paucartambo & Paucartambo & 3020 & $13^{\circ} 07^{\prime} 00^{\prime \prime}$ & $71^{\circ} 35^{\prime} 00^{\prime \prime}$ & Che'qche Paspa añu \\
\hline ACC 079 & cusco & Chumbivilcas & Velille y santotomas & Velille y santotomas & 3360 & $14^{\circ} 27^{\prime} 03^{\prime \prime}$ & $72^{\circ} 04^{\prime} 57^{\prime}$, & No definido \\
\hline ACC 081 & Cusco & Espinar & Yauri & Machupueste espinar & 3927 & $14^{\circ} 48^{\prime} 05^{\prime}$ & $71^{\circ} 25^{\prime} 42^{\prime \prime}$ & No definido \\
\hline ACC 082 & Cusco & Espinar & Yauri & Machupueste espinar & 3927 & $14^{\circ} 48^{\prime} 05^{\prime}$ & $71^{\circ} 25^{\prime} 42^{\prime \prime}$ & No definido \\
\hline ACC 083 & Cusco & Espinar & Yauri & Machupueste espinar & 3927 & $14^{\circ} 48^{\prime} 05^{\prime}$ & $71^{\circ} 25^{\prime} 42^{\prime \prime}$ & No definido \\
\hline ACC 085 & Cusco & Espinar & Yauri & Chañi pichigua espinar & 3927 & $14^{\circ} 48^{\prime} 05^{\prime}$ & $71^{\circ} 25^{\prime} 42^{\prime \prime}$ & No definido \\
\hline ACC 086 & Cusco & Paucartambo & Paucartambo & Paucartambo & 3020 & $13^{\circ} 07^{\prime} 00^{\prime \prime}$ & $71^{\circ} 35^{\prime} 00^{\prime \prime}$ & Zapallo añu \\
\hline ACC 087 & Cusco & Calca & Pisac & Viacha & 4200 & $13^{\circ} 21^{\prime} 40^{\prime \prime}$ & $71^{\circ} 49^{\prime} 28^{\prime \prime}$ & Yana ñahui \\
\hline ACC 088 & Cusco & Paucartambo & Paucartambo & Paucartambo & 3020 & $13^{\circ} 07^{\prime} 00^{\prime \prime}$ & $71^{\circ} 35^{\prime} 00^{\prime \prime}$ & Yana ñahui \\
\hline ACC 089 & Cusco & Calca & Pisac & Amaru & 3500 & $13^{\circ} 23^{\prime} 00^{\prime \prime}$ & $71^{\circ} 50^{\prime} 00^{\prime \prime}$ & Yana ñahui \\
\hline ACC 091 & Cusco & Calca & Lamay & Huama & 3692 & $13^{\circ} 20^{\prime} 14,3^{\prime \prime}$ & $71^{\circ} 52^{\prime} 11^{\prime \prime}$ & yana ñahui cheqche \\
\hline ACC 092 & Cusco & Calca & Lamay & Huama & 3692 & $13^{\circ} 20^{\prime} 14,3^{\prime \prime}$ & $71^{\circ} 52^{\prime} 11^{\prime \prime}$ & yana waca waqra \\
\hline ACC 093 & Cusco & Calca & Lamay & Huama & 3692 & $13^{\circ} 20^{\prime} 14,3^{\prime \prime}$ & $71^{\circ} 52^{\prime} 11^{\prime \prime}$ & Cheqche añu \\
\hline ACC 095 & Cusco & Paucartambo & Collquepata & Miskawara & 3020 & $13^{\circ} 19^{\prime} 12^{\prime \prime}$ & $71^{\circ} 35^{\prime} 34^{\prime \prime}$ & Yana tata añu \\
\hline ACC 096 & Cusco & Paucartambo & Collquepata & Miskawara & 3020 & $13^{\circ} 19^{\prime} 12^{\prime \prime}$ & $71^{\circ} 35^{\prime} 34^{\prime \prime}$ & Yana ñahui \\
\hline ACC 098 & Cusco & Paucartambo & Collquepata & Miskawara & 3020 & $13^{\circ} 19^{\prime} 12^{\prime \prime}$ & $71^{\circ} 35^{\prime} 34^{\prime \prime}$ & Okuko maki \\
\hline ACC 099 & Cusco & Canchis & San pablo & Santa Barbara & 3486 & $14^{\circ} 12^{\prime} 00^{\prime \prime}$ & $71^{\circ} 14^{\prime} 12^{\prime \prime}$ & No definido \\
\hline ACC 100 & Cusco & Canchis & San pablo & Santa Barbara & 3486 & $14^{\circ} 12^{\prime} 00^{\prime \prime}$ & $71^{\circ} 14^{\prime} 12^{\prime \prime}$ & No definido \\
\hline ACC 101 & Cusco & Canchis & San pablo & Santa Barbara & 3486 & $14^{\circ} 12^{\prime} 00^{\prime \prime}$ & $71^{\circ} 14^{\prime} 12^{\prime \prime}$ & No definido \\
\hline ACC 103 & Cusco & Canas & Layo & Layo & 4115 & $14^{\circ} 13^{\prime} 05^{\prime \prime}$ & $71^{\circ} 25^{\prime} 54^{\prime \prime}$ & No definido \\
\hline ACC 104 & Cusco & Canas & Layo & Layo & 4115 & $14^{\circ} 13^{\prime} 05^{\prime \prime}$ & $71^{\circ} 25^{\prime} 54^{\prime \prime}$ & No definido \\
\hline ACC 105 & Cusco & Canas & Layo & Layo & 4115 & $14^{\circ} 13^{\prime} 05^{\prime \prime}$ & $71^{\circ} 25^{\prime} 54^{\prime \prime}$ & No definido \\
\hline
\end{tabular}




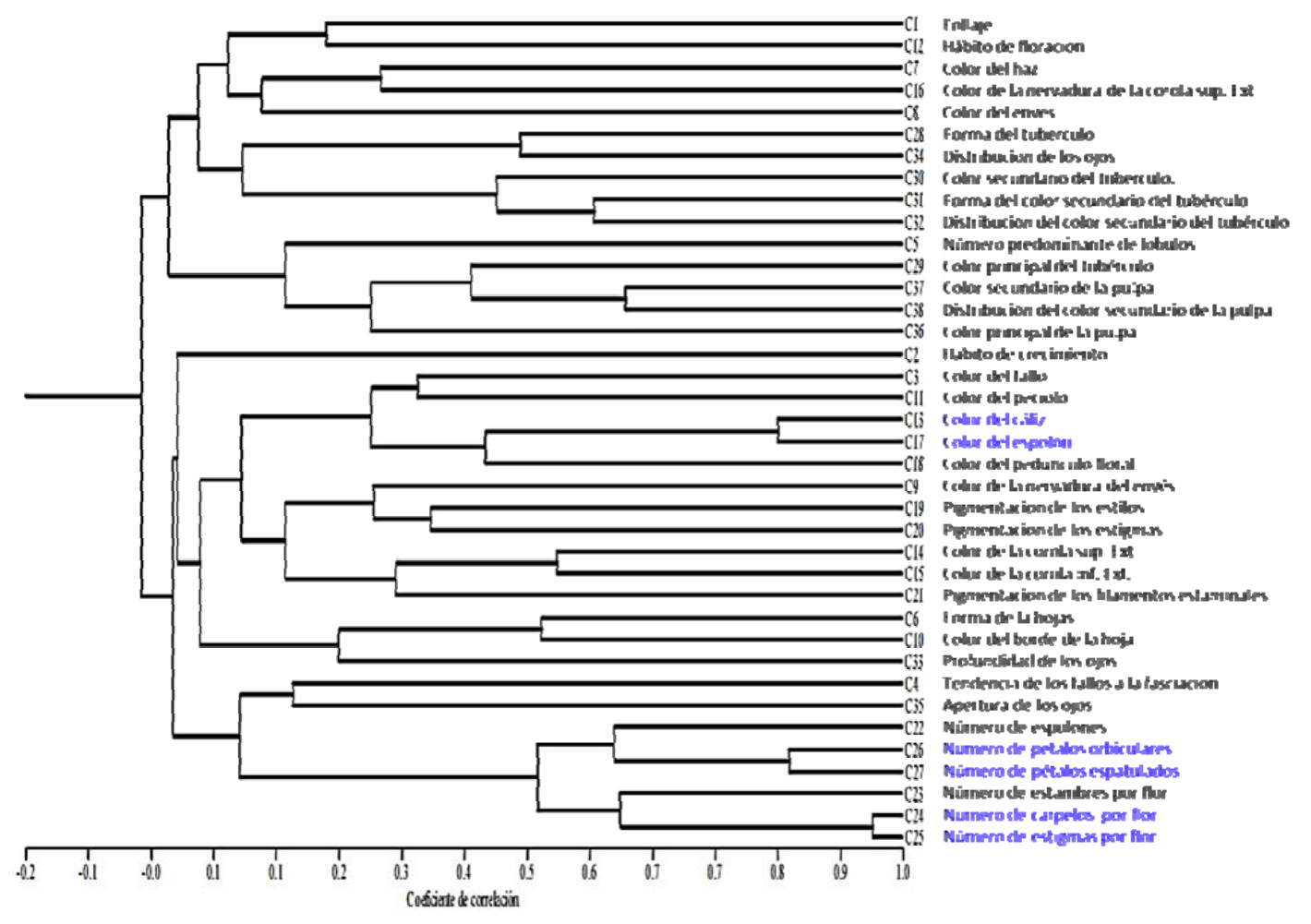

Figura 2. Dendograma del análisis correlación de caracteres morfológicos.

Caracterización Morfológica.

La caracterización morfológica se realizó en dos etapas: en plena floración (con caracteres de la parte aérea de la planta) y después de la cosecha (con caracteres de tubérculos), con ayuda de la carta de colores de la Royal Horticultural Society (RHSCC). En la primera etapa se evaluaron 3 plantas por cada accesión a los 172 días después de la siembra, cuando más del $50 \%$ de las plantas se encontraban en floración. La segunda fue inmediatamente después de la cosecha evaluando 5 tubérculos por cada accesión. En el estudio de la variabilidad morfológica se utilizó el coeficiente de distancia taxonómica y para la construcción del fenograma se empleó el método de agrupamiento promedio UPGMA (Sokal \& Michener, 1958).

\section{Resultados.}

Análisis de los caracteres morfológicos.

De los 44 caracteres morfológicos estudiados seis fueron excluidos para la caracterización morfológica (Tabla 2) porque en las evaluaciones preliminares no presentaron variación en el germoplasma (la forma del tallo, pubescencia y enroscamiento del tallo) ni uniformidad en una misma planta (el color del follaje, de la estípula y el color de los pétalos). Para determinar los caracteres que no contribuyen en la variación se calcularon los coeficientes de variabilidad, siendo la tendencia de los tallos a la fasciación, la forma de hojas, el color del envés y del borde de las hojas, no considerados para el análisis de variabilidad morfológica por presentar valores inferiores al 20 \% (López et al., 2008). Con el análisis de correlación de Pearson (Figura 2), se consideraron caracteres altamente correlacionados: el color del espolón con el color del cáliz, el número de estigmas con el número de carpelos, y el número de pétalos espatulados con el número de pétalos orbiculares; por presentar valores superiores al 70 \% (López et al., 2008); de los cuales, para el análisis de variabilidad solo se consideró al color del cáliz, el número de estigmas y el número de pétalos orbiculares por su fácil observación. En el Análisis de Componentes Principales se observó que los 14 primeros componentes estarían explicando solamente el $75 \%$ de la variación total, y presentan valores propios superiores a 1 (Tabla 3). Asimismo, en la Tabla 4 se presenta la contribución relativa de los caracteres a la variabilidad por medio de sus factores de carga; los factores de carga de mayor valor absoluto (Superior a 0.46) fueron: abundancia de follaje, color del tallo, número predominante de lóbulos por hoja, color del haz de la hoja, color del peciolo, hábito de floración, color del cáliz, color de la corola superior externa, color de la corola inferior externa, color de la nervadura de la corola superior externa, color del 
espolón, color de la nervadura de la corola superior externa, color del espolón, color del pedúnculo floral, pigmentación de los estigmas, pigmentación de los filamentos estaminales, número de espolones, número de estambres por flor, número de carpelos, número de estigmas por flor, número de pétalos orbiculares, número de pétalos espatulados, color principal del tubérculo, forma del color secundario del tubérculo, distribución del color secundario, color principal de la pulpa, color secundario de la pulpa, distribución del color secundario de la pulpa y apertura de los ojos del tubérculo.

Análisis de la variabilidad morfológica de 89 accesiones de añu.

El análisis de agrupamiento generó 89 morfotipos estructurados en cuatro grupos a un coeficiente de distancia de 1.45, sin la presencia de duplicados (Figura 3). Como se observa en la Tabla 5, todas las accesiones del grupo I presentan color secundario del tubérculo y se subdividen en 3 subgrupos; el subgrupo IA. 1 conformado por 38 accesiones que presentan tubérculos de color amarillo y amarillo anaranjado, con pulpa de color anaranjado; el subgrupo IA.2 integrado por 27 accesiones con tubérculos de color blanco amarillento, amarillo claro y amarillo, con pulpa de color blanco, amarillo claro y amarillo; y el subgrupo IB con una sola accesión de tubérculo y pulpa de color anaranjado. El grupo II está constituido por 11 accesiones que presentan tubérculos de color amarillo claro, amarillo y amarillo anaranjado, sin color secundario. El grupo III constituido por 9 accesiones con tubérculos de color púrpura grisáceo y rojo grisáceo con color secundario irregularmente distribuido. El grupo IV está conformado por 3 accesiones con tubérculos de color púrpura grisáceo y negro sin color secundario a excepción de la accesión 58 que presenta color secundario en forma de bandas.
Tabla 2. Caracteres morfológicos utilizados en el estudio.

\begin{tabular}{|c|c|c|c|}
\hline Estructura & Caracteres morfológicos & $\begin{array}{l}\text { Coeficiente } \\
\text { variabilidad }\end{array}$ & Estado de uso \\
\hline \multirow{4}{*}{ Follaje } & Abundancia & 0.425 & Utilizado \\
\hline & Color & & $*$ \\
\hline & Hábito de crecimiento & 0.356 & Utilizado \\
\hline & Forma & & * \\
\hline \multirow{4}{*}{ Tallo } & Color & 0.325 & Utilizado \\
\hline & Fasciación & 0.175 & $* *$ \\
\hline & Pubescencia & & $*$ \\
\hline & Enroscamiento & & $*$ \\
\hline \multirow{8}{*}{ Hoja } & $\begin{array}{l}\text { Número predominante de lóbulos } \\
\text { por hoja }\end{array}$ & 0.394 & Utilizado \\
\hline & Forma & 0.145 & $* *$ \\
\hline & Color del haz & 0.311 & Utilizado \\
\hline & Color del envés & 0.104 & ** \\
\hline & Color de la nervadura del envés & 0.338 & Utilizado \\
\hline & Color del borde de la hoja & 0.075 & $* *$ \\
\hline & Color del peciolo & 0.286 & Utilizado \\
\hline & Color de la estipula & & $*$ \\
\hline \multirow{22}{*}{ Flor } & Hábito de floración & 0.458 & Utilizado \\
\hline & Color de pétalos & & $*$ \\
\hline & Color del cáliz & 0.393 & Utilizado \\
\hline & $\begin{array}{l}\text { Color de la corola superior } \\
\text { externa }\end{array}$ & 0.33 & Utilizado \\
\hline & $\begin{array}{l}\text { Color de la corola inferior } \\
\text { externa }\end{array}$ & 0.32 & Utilizado \\
\hline & $\begin{array}{l}\text { Color de la nervadura de la corola } \\
\text { superior externa }\end{array}$ & 0.389 & Utilizado \\
\hline & Color del espolón & 0.389 & $* * *$ \\
\hline & Color del pedúnculo & 0.326 & Utilizado \\
\hline & Pigmentación de los estilos & 2.757 & Utilizado \\
\hline & Pigmentación de los estigmas & 1.19 & Utilizado \\
\hline & $\begin{array}{l}\text { Pigmentación de los filamentos } \\
\text { estaminales }\end{array}$ & 0.635 & Utilizado \\
\hline & Número de espolones & 0.362 & Utilizado \\
\hline & Número de estambres & 0.342 & Utilizado \\
\hline & Número de carpelos & 0.726 & $* * *$ \\
\hline & Número de estigmas & 0.716 & Utilizado \\
\hline & $\mathrm{N}^{\circ}$ de pétalos orbiculares & 0.252 & Utilizado \\
\hline & $\mathrm{N}^{\circ}$ de pétalos espatuados & 0.252 & $* * *$ \\
\hline & Forma & 0.394 & Utilizado \\
\hline & Color principal & 0.549 & Utilizado \\
\hline & Color secundario & 0.547 & Utilizado \\
\hline & Forma del color secundario & 0.601 & Utilizado \\
\hline & Distribución del color secundario & 0.544 & Utilizado \\
\hline \multirow[t]{6}{*}{ Tubérculo } & Profundidad de los ojos & 0.266 & Utilizado \\
\hline & Distribución de los ojos & 0.28 & Utilizado \\
\hline & Apertura de los ojos & 0.335 & Utilizado \\
\hline & Color principal de la pulpa & 0.421 & Utilizado \\
\hline & Color secundario de la pulpa & 0.957 & Utilizado \\
\hline & Distribución del color secundario & 0.839 & Utilizado \\
\hline
\end{tabular}

* Caracteres que fueron descartados en las evaluaciones preliminares por no ser uniformes en el germoplasma o presentar variación en una misma planta.

** Caracteres que fueron descartados por presentar baja variación en el germoplasma.

*** Caracteres que fueron descartados por estar correlacionados a otros de más fácil evaluación. 


\section{Discusión.}

De los 44 caracteres estudiados en el germoplasma, seis de ellos no presentaron variación, o no mostraron estabilidad dentro de una misma planta, por lo que fueron descartados para la evaluación. Es posible que dichos caracteres no muestren variabilidad ni estabilidad en caracterizaciones posteriores de añus de la Región Cusco. Los caracteres que mostraron coeficientes de variabilidad inferiores al 20\% (Tabla 2), de acuerdo a lo recomendado por López et al. (2008), tampoco fueron considerados para la caracterización, sin embargo, se sugiere que el uso de dichos caracteres debe ser evaluado previamente en futuros trabajos de caracterización. Así mismo, mediante el análisis de correlación se eliminaron otros tres caracteres por estar altamente correlacionados cada uno de ellos con otros caracteres de más fácil observación (Figura 2).

En el análisis de componentes principales, se observa que de los caracteres que no fueron descartados (Tablas 2 y 4), 25 de ellos son los de mayor contribución a la variación total (por medio de sus factores de carga superiores a 0.46 en los 14 primeros componentes); 12 de los cuales son de la flor, 8 del tubérculo, 3 de la hoja, 1 del tallo y 1 del follaje (Tabla 4). Sin embargo, en una caracterización previa de añus realizada por Gaspar (1998), no utilizaron caracteres de la flor, reportando que mejor evalúan la variación dentro de su germoplasma los caracteres de tubérculo, tallo y hoja. Igualmente, Durand (2005), reportó como mejores a los caracteres de tallo, hoja y tubérculo. Teniendo en cuenta que la mayoría de los caracteres del primero y segundo componente corresponden a los de la flor, se recomendaría que estos sean considerados para formar parte de una futura lista de descriptores de añu.

Respecto al origen de la mayor variabilidad presente en los caracteres de los tres primeros componentes (de la flor, color secundario del tubérculo y del color de la pulpa,) que se observan sombreados de colores en la Tabla 5, podría deberse a la poca importancia que los agricultores dan a dichos caracteres durante la selección de sus semillas para la siembra, y al flujo de genes producto de la convivencia del añu con sus parientes silvestres que podría estar ocurriendo en las zonas de estudio. El escaso interés por los caracteres del color de tubérculo del añu en la selección, reflejaría su uso principal para el autoconsumo y como alimento de animales, para los cuales el aspecto del producto es poco importante.

En el análisis de componentes principales la variación acumulada en el tercer componente fue de 30\% (Tabla 3), mientras que Durand (2005) también para el añu reporta $47.87 \%$, sin embargo, en trabajos equivalentes realizados en papa (Solanum spp.) se obtuvieron valores de 79.12\% (Borrego et al., 1999) y en tejocote (Crataegus spp.) 59.77\% (López et al., 2008). Los valores de variación acumulada obtenidos son más bajos en los trabajos con el añu, lo que se explicaría por la elevada variabilidad y el escaso agrupamiento del germoplasma, además, que el conjunto de caracteres utilizados estarían evaluando y diferenciando efectivamente a la mayor parte del germoplasma de añu.

En el análisis de la variabilidad realizado a las 89 accesiones de añu no se encontraron duplicados (Figura 2), que hace suponer que exista una alta variabilidad morfológica en este cultivo. Estos resultados coinciden con la evaluación realizada por Moscoso (2007), quien utilizando 80 descriptores morfológicos y agronómicos no encontró duplicados en las accesiones de Cusco. La amplia variabilidad morfológica del cultivo de añu es también reportada por diferentes investigadores quienes caracterizaron añus provenientes de diferentes zonas del Perú, Ecuador y Bolivia (Olivera, 1968; Ponce, 1995; Gonza, 1998; Durand, 2005). El origen de la elevada variabilidad morfológica del añu podría explicarse porque a pesar de propagarse vegetativamente aún mantiene su reproducción sexual (Grau et al., 2003), lo cual, sumado a la forma de manejo de la semilla asexual que realizan los agricultores tradicionales quienes acostumbran mezclar sus cultivares; esto podría estar influenciando en la estructura y diversidad genética de este cultivo. Particularmente si el añu todavía es capaz de reproducirse sexualmente, no se excluye que los agricultores mantengan los genotipos provenientes de la reproducción sexual y los utilizan para la propagación vegetativa, como en caso de la yuca (Elias et al., 2001) o las papas andinas (Quirós et al., 1992). Este tipo de costumbres da como resultado, nuevos genotipos y fenotipos que son producidos y

Tabla 3. Análisis de Componentes Principales.

\begin{tabular}{cccc}
\hline $\begin{array}{c}\text { Componente } \\
\text { Principal }\end{array}$ & $\begin{array}{c}\text { Valores } \\
\text { propios }\end{array}$ & Porcentaje & $\begin{array}{c}\text { Porcentaje } \\
\text { acumulado }\end{array}$ \\
\hline 1 & 5.0634436 & 13.3249 & 13.3249 \\
2 & 3.7057156 & 9.7519 & 23.0767 \\
3 & 2.81752114 & 7.4145 & 30.4913 \\
4 & 2.53893322 & 6.6814 & 37.1727 \\
5 & 2.11716551 & 5.5715 & 42.7442 \\
6 & 1.96583682 & 5.1733 & 47.9174 \\
7 & 1.69958775 & 4.4726 & 52.39 \\
8 & 1.60141295 & 4.2142 & 56.6043 \\
9 & 1.51677701 & 3.9915 & 60.5958 \\
10 & 1.3158122 & 3.4627 & 64.0584 \\
11 & 1.13516907 & 2.9873 & 67.0457 \\
12 & 1.08953381 & 2.8672 & 69.9129 \\
13 & 1.08262745 & 2.849 & 72.7619 \\
& 1.02437857 & 2.6957 & 75.4577 \\
15 & 0.93617958 & 2.4636 & 77.9213 \\
16 & 0.82378792 & 2.1679 & 80.0892 \\
17 & 0.80918815 & 2.1294 & 82.2186 \\
18 & 0.75962148 & 1.999 & 84.2176 \\
19 & 0.70719344 & 1.861 & 86.0786 \\
20 & 0.62839825 & 1.6537 & 87.7323 \\
\hline
\end{tabular}

Se indica sombreado el componente a partir del cual el valor propio es superior a $1 \mathrm{y}$ el porcentaje acumulado superior a $75 \%$. 
Tabla 4. Matriz factorial para los 14 primeros Componentes Principales.

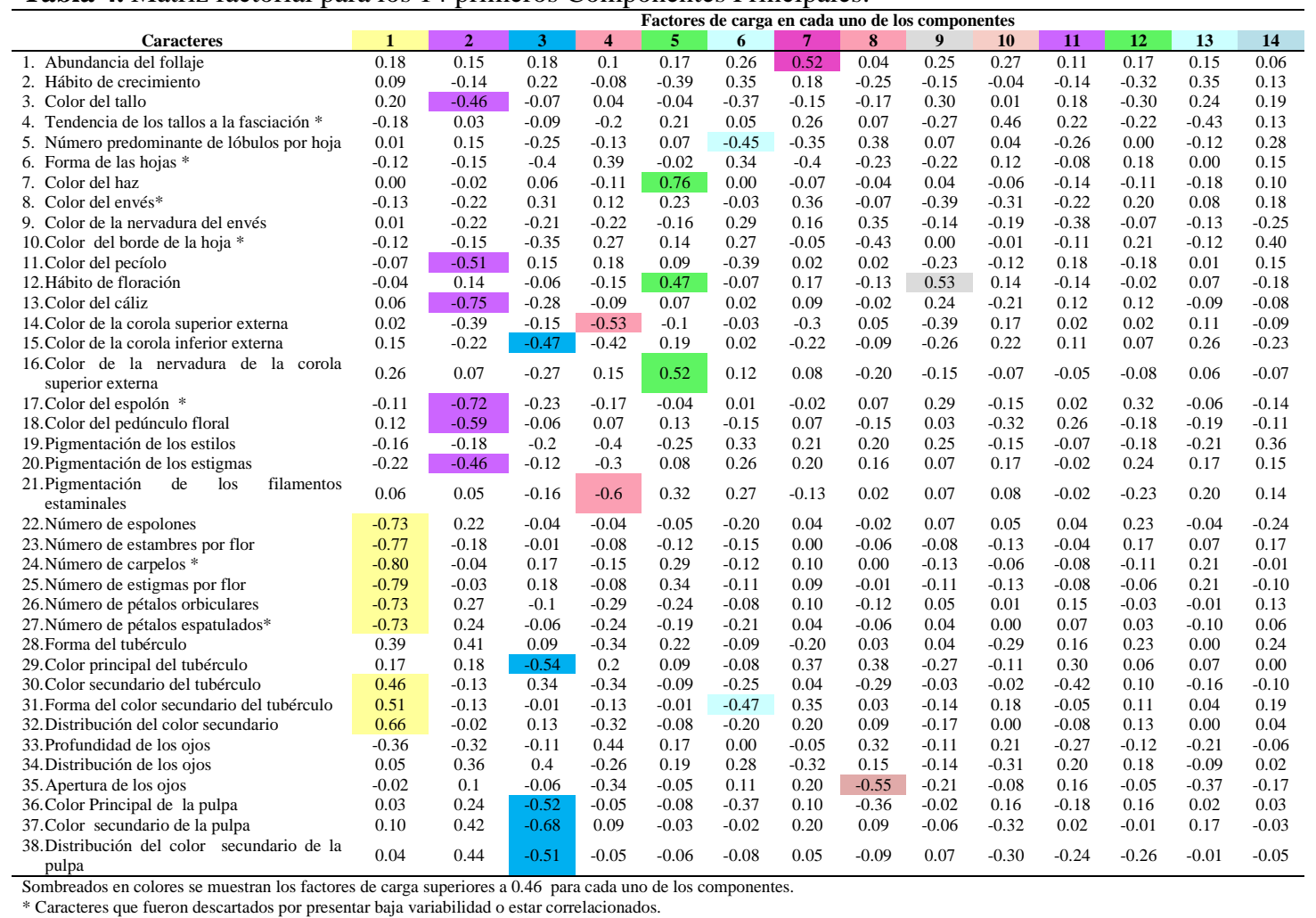

seleccionados por los agricultores de acuerdo a las características agromorfológicas interesantes. También, otro elemento clave de los sistemas agrícolas andinos que influye en la diversidad genética y estructura de los tubérculos andinos es el intercambio de los tubérculos entre los agricultores y las comunidades, estos pueden ser por regalo, trueque, “ayni”, como forma de pago por trabajo o la compra en mercados o ferias dentro de la comunidad o comunidades vecinas, existiendo una dinámica constante de intercambio y provisión de semillas. Los agricultores pueden intercambiar las semillas a pequeña escala (dentro de un microcentro de la diversidad), o a mayor escala (ferias de biodiversidad y de los mercados) (Terrazas \& Valdivia, 1998). Además, esta amplia diversidad del añu podría explicarse por la convivencia de los cultivares con sus parientes silvestres y landraces que permitiría el flujo de genes y por lo tanto, la presencia de numerosos morfotipos en una pequeña zona de estudio.

En el análisis de agrupamiento se puede apreciar que dentro de los grupos I y II (añus claros) existe una menor distancia (Figura 3), por tanto, una menor variabilidad que sería consecuencia de una mayor presión de selección sobre pocos caracteres. Mientras que la mayor distancia, es decir mayor variabilidad dentro de los grupos III y IV (añus oscuros) sería el resultado de no estar sometidos a selección (Figura 3), sin embargo, su permanencia también podría estar relacionada a su uso en algún tipo de tradición o a la conservación de sus caracteres dentro de los añus silvestres.

\section{Conclusiones.}

Los caracteres morfológicos cualitativos de la flor y los del color principal y secundario de tubérculo fueron los que más contribuyeron a la variación, por lo tanto, podrían ser considerados dentro de una futura lista de descriptores para la caracterización morfológica del añu.

A pesar de ser el añu un cultivo subutilizado, la elevada variabilidad morfológica observada en las accesiones de la Región Cusco indicaría la presencia en esta zona de un mecanismo que la genera $y$ mantiene, el que podría estar relacionado a su reproducción sexual y a la forma del manejo de la semilla asexual que realizan los agricultores. Además, existe una mayor variabilidad dentro de los grupos de añus oscuros (rojo grisáceo, púrpura grisáceo y negro) que en los claros (blanco amarillento, amarillo, amarillo claro, amarillo, amarillo anaranjado y anaranjado). 
Tabla 5. Descripción de los grupos morfológicos.

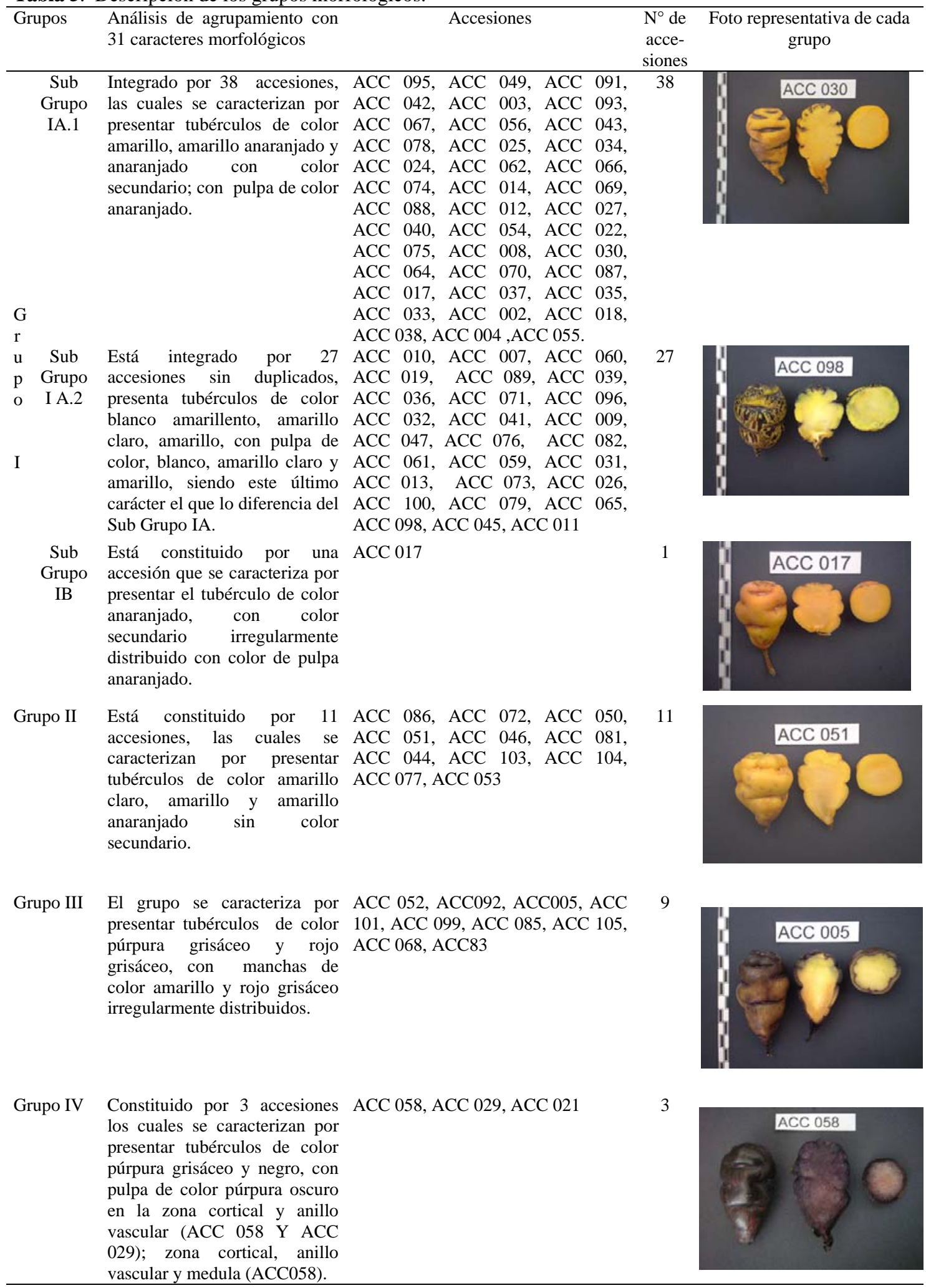

Los grupos morfológicos se generaron con un coeficiente de distancia de 1.5 del fenograma de la Figura 2. 


\section{Agradecimientos.}

A los agricultores de las Comunidades Campesinas de Amaru, Paru Paru y Viacha por trasmitir sus conocimientos tradicionales; por el esfuerzo y apoyo en el establecimiento, mantenimiento y conservación del cultivo.

Al Conseil interuniversitaire de la Communauté française de Belgique (CIUF) por el apoyo financiero.

\section{Literatura citada.}

Borrego E. F., Fernández B. I., López B. A., Parga T. V., Murillo S. M. \& Carvajal A. A., 1999. Correlación y componentes principales de variación en variedades de papa (Solanum tuberosum L.). Agronomía Mesoamericana. 10 (2): 01-06.

Campos D., Noratto G., Chirinos R., Arbizu C., Roca W., Cisneros L. \& Zevallos. 2006. Antioxidant capacity and secondary metabolites in four species of Andean tuber crops: native potato (Solanum sp.), mashua (Tropaeolum tuberosum Ruiz \& Pavon), Oca (Oxalis tuberosa Molina) and ulluco (Ullucus tuberosus Caldas). J Sci Food Agric 86:1481-1488.

Durand E. 2005. Caracterización morfológica de la Oca, Olluco y mashua manejadas por los campesinos de las comunidades de Picol, Matinga, Qquecayoc, Poques, Chumpe y Sayllafaya. Tesis para optar al Título profesional de Ingeniero Agronomo, Universidad Nacional de San Antonio Abad del Cusco, Perú. P. 227.

Elias M., Penet L., Vindry P., McKey D., Panaud O. \& Robert T. 2001. Unmanaged sexual reproduction and the dynamics of genetic diversity of a vegetatively propagated crop plant, cassava (Manihot esculenta Crantz), in a traditional farming system. Mol. Ecol. 10:1895-1907.

Espinoza E., Monteghirfo S. \& Mario G. 1999. Determinación de la composición de aminoácidos de mashua (Tropaeolum tuberosum) mediante cromatografía líquida de alta perfonmance (HPLC). Boletin de la Sociedad Quimica del Perú; Vol. LXV; Diciembre 1999.

Gaspar S. 1998. Caracterización morfológica y nivel de ploidía en cultivares de Oca (Oxalis tuberosa M.), Papalisa (Ullucus tuberosus C.), e Isaño (Tropaeolum tuberosum R.) Tesis Ing. Agronómica, Universidad Mayor de San Simón, Bolivia. 122p.

Gibbs P.E., Marshall D. \& Brunton D. 1978. Studies on the cytology of Oxalis tuberosa and Tropaeolum tuberosum. Notes from the Royal Botanic Garden, Edinburgh 37(1):215-220.

Gonza A. 1998. Caracterización agronómica de 297 entradas de maswa (Tropaeolum tuberosum R \& P) del Banco de Germoplasma del CICA. Tesis para optar el título profesional de Ingeniero Agrónomo, Universidad Nacional de San Antonio Abad del Cusco, Perú.

Grau A., Ortega R., Nieto C. \& Hermann M. 2003. Mashua (Tropaeolum tuberosum Ruíz \& Pav.). Promoting the conservation and use of underutilized and neglected crops. 25. International Potato Center, Lima,
Peru/International Plant Genetic Resources Institute, Rome, Italy.

Hasegawa T., Nishino H. \& Iwashima A. 1992. Isotiocyonates inhibit cell cycle progression of $\mathrm{HeLa}$ cell at G sub (2)/M phase. Anti-Cancer-Drug 4:273-279.

Johns T., Kitts W.D., Newsome F. \& Towers G. H. N. 1982. Anti-reproductive and other medicinal effects of Tropaeolum tuberosum. Journal of Ethnopharmacology 5:149-161.

King S. R. 1987. Four endemic Andean tuber crop: promising food resources for agricultural diversification. Mountain Res. And Devel. 7 (1):43-52.

López-Santiago J., Nieto-Angel R., Barrientos-Priego A. F., Rodríguez-Pérez E., Colinas-León M. T., Borys M. W. \& Gonzalez-Andrés F. 2008. Selección de variables morfológicas para la caracterización del Tejocote (Crataegus spp.). Revista Chapingo Serie Horticultura 14(2): 97-111.

Moscoso E. 2007. Conservación In Situ y caracterización morfológica de cultivares de Tropaeolum tuberosum $R$. $\& P$. (añu) en las Comunidades de Amaru, Paru Paru Viacha-Calca-Cusco, tesis para optar al título profesional de Biólogo. Universidad Nacional San Antonio Abad del Cusco, Lima, Perú.

Olivera R. 1968. Variabilidad morfológica de Tropaeolum tuberosum Añu y clave de identificación de los clones. Tesis para optar el título profesional de Ingeniero Agronomo, Universidad Nacional de San Antonio Abad del Cusco, Perú.

Ortega O., Kliebenstein D., Arbizu C., Ortega O. \& Quiroz C. 2006. Glucosinolate Survey of Cultivades and Feral Mashua (Tropaeolum tuberosum Ruiz \& Pavón) in the Cuzco Region of Peru. Economic Botany 60(2): 000000.

Pintao A.M., Pais M.S.S., Coley H., Kelland L.R. \& Judson I.R. 1995. In vitro an invitro anti-tumor activity of bencylisothiocyanate: Anatural product from Tropeolum majus. Pnat Med. 61:233-236.

Ponce A. 1995. Colección, conservación y evaluación de la biodiversidad de los tuberculos andinos: Oca (Oxalis tuberosa), Olluco (Ullucus tuberosus), y mashua (Tropaeolum tuberosum), en Pasco y Huanuco. Sociedad Peruana de genética. Resumenes del tercer congreso peruano de genética. Lima, Perú. p. 45-46.

Quirós C. F., Ortega R., Van Raamsdonck L., Herrera M. M., Cisneros P., Shmid E. \& Brush S. B., 1992. Increase of Potato Genetic resourses in their center of diversity: The role of natural outcrossing and selection by the Andean farmers. Genet. Resour. Crop Evol. 39: 107113.

Rohlf F. J. 2000. NTSYS pc: Numerical Taxonomy and Multivariate Analysis System, version 2.1. Department of Ecology and Evolution State University of New York.

Sokal R.R. \& Michener C.D. 1958. A statistical method for evaluating systematic relationships. Univ. Kansas Sci. Bull. 38:1409-1438.

Terrazas F. \& Valdivia F. 1998. Spatial dynamics of in situ conservation: handling the genetic diversity of Andean tubers in mosaic systems. Plant Genetic Resources Newsletter 114:9-15. 


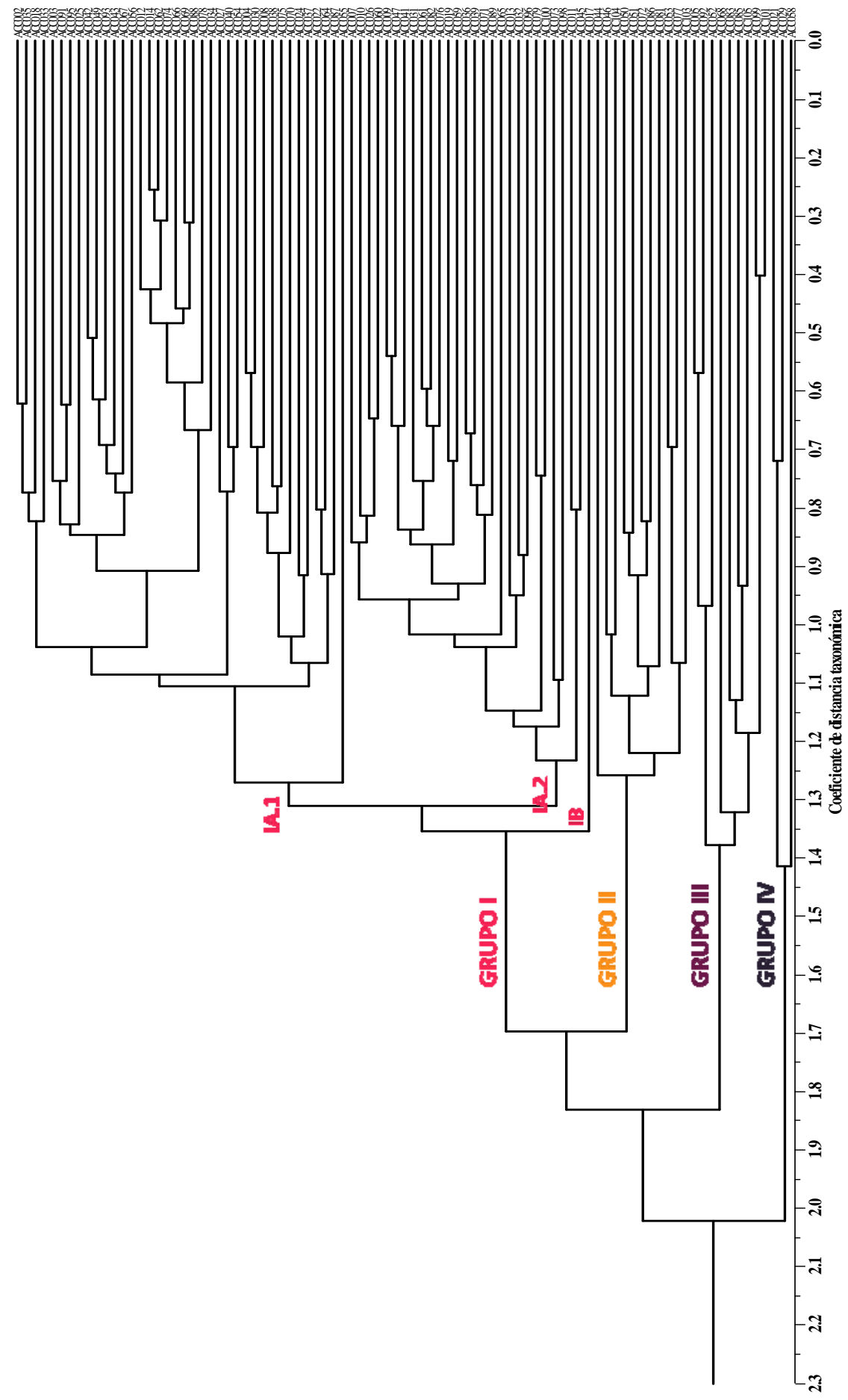

Figura 3. Fenograma de las 89 accesiones de añu.

IA.1, IA2 y IB son los subgrupos del grupo I. 


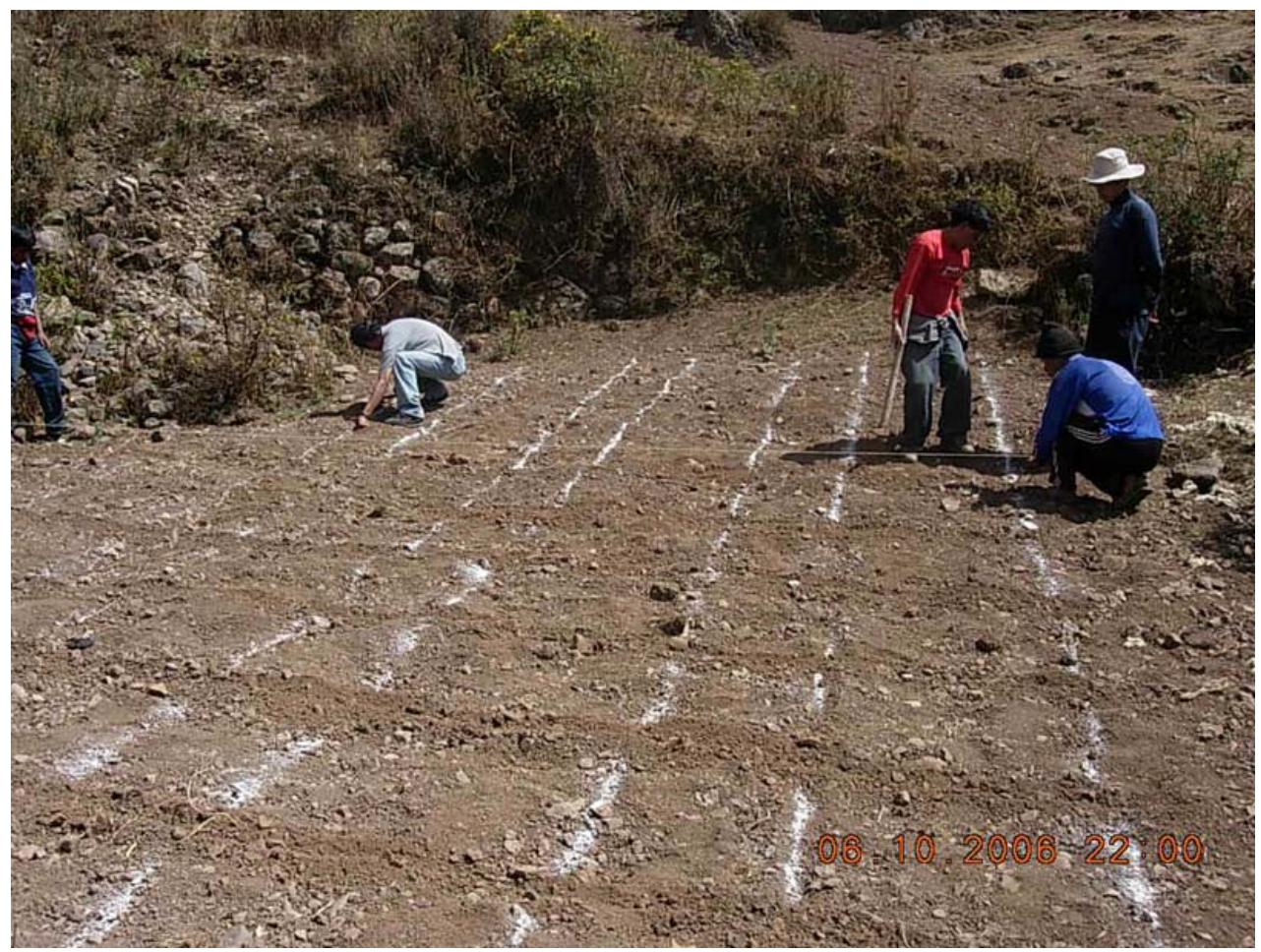

Anexo 1. El diseño de la parcela se realizó antes de la siembra, con las siguientes medidas: calles de $0.50 \mathrm{~m}$ de ancho, los surcos de $0.90 \mathrm{~m}$ de largo y la distancia entre surcos fue de $0.90 \mathrm{~m}$.

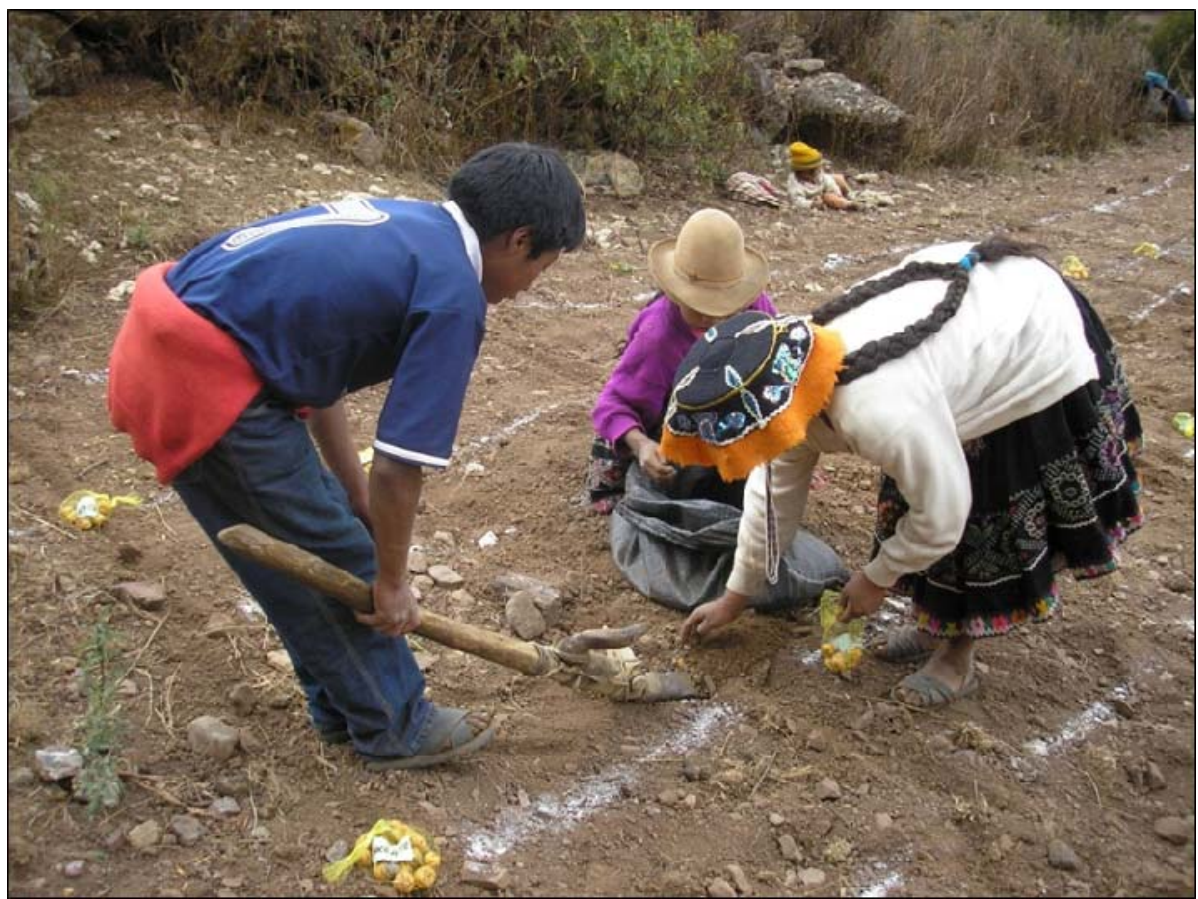

Anexo 2. Se observa la siembra o Tarpuy realizada de forma tradicional, los hombres con la chakitaqlla y las mujeres depositando los tubérculos en los surcos. 
${ }^{1}$ Universidad Nacional Agraria La Molina, Instituto de Biotecnología. Área de Biología Molecular. Av. La Molina s/n, Lima Perú. cinthiashe@gmail.com.

${ }^{2}$ Universidad Nacional Agraria La Molina, Facultad de Ciencias. Av. La Molina s/n, Lima Perú. rmansilla@lamolina.edu.pe.

${ }^{3}$ Universidad Nacional San Antonio Abad del Cusco, Facultad de Biología. Av. La Cultura s/n, Cusco Perú. americochacon@hotmail.com.

${ }^{4}$ Universidad Nacional Agraria La Molina, Facultad de Agronomía. Av. La Molina s/n, Lima Perú. rblas@lamolina.edu.pe. 